\title{
The Effects of Pre-Analytical Processing and Storage on Bovine Blood D- and L-Lactate Concentrations
}

\author{
Binbing Ling ${ }^{1}$, Jennifer Wright ${ }^{1}$, Kimberley Buker ${ }^{2}$, Jane Alcorn ${ }^{3}$, Gordon Zello ${ }^{1}$ and \\ Katharina Lohmann ${ }^{*}, 2$
}

\author{
${ }^{I}$ Division of Nutrition and Dietetics, College of Pharmacy and Nutrition, ${ }^{2}$ Department of Large Animal Clinical \\ Sciences, Western College of Veterinary Medicine, ${ }^{3}$ Division of Pharmacy, College of Pharmacy and Nutrition, \\ University of Saskatchewan, Saskatoon, SK S7N 5C9, Canada
}

\begin{abstract}
To investigate processing- and storage-dependent changes in D- and L-lactate concentration, blood samples from eleven healthy Holstein calves were spiked with $3 \mathrm{mM}$ D-lactic acid and $3 \mathrm{mM}$ L-lactic acid immediately following collection (time 0) or left untreated for comparison. Serum and plasma, respectively, were separated 0.5 hours following collection or left in contact with blood cells, stored at $4^{\circ} \mathrm{C}$ and analyzed for D- and L-lactate concentration using enzymatic assays at 1,2, 4, 8, 12, 24, and 48 hours. Concentrations were compared to the 1 hour sample. D- and L-Lactate concentrations in all separated samples were stable for up to 48 hours. When left in contact with cells, L-lactate concentration in untreated and spiked serum and in spiked plasma, D-Lactate concentration in untreated serum, and total lactate concentration in untreated serum increased significantly by 48 hours.
\end{abstract}

Keywords: Specimen Collection, centrifugation, lactate isomers, serum, plasma, storage.

\section{INTRODUCTION}

Lactate is a hydroxycarboxylic acid and exists as two stereoisomers, L-lactate and D-lactate. Under healthy physiological conditions, L-lactate is the major isomer found in blood whereas D-lactate is present in very low concentrations [1,2]. Supra-physiological levels of both isomers may result from excessive lactate production and/or impaired elimination [3-5], which, in turn, may lead to severe D- or L-lactic acidosis $[4,6]$. Disease states, including diarrhea, can contribute to lactic acidosis and are a significant cause of illness and death in young animals and children [7-10]. Lactic acidosis is also a potential side effect of several pharmaceutical treatments including the use of metformin in diabetic patients [11-13]. Only within the past decade has the literature recognized the significance of high concentrations of D-lactate [14-16]. D-Lactic acidosis (serum D-lactate $>3 \mathrm{mM}$ ) has been documented in diarrheic lambs and goat kids, and humans with short bowel syndrome [17-19]. The clinical presentation of D-lactic acidosis differs from that of L-lactic acidosis and includes altered mental and physical states such as weakness, ataxia, impaired posture and behaviour, and in severe cases, acute encephalopathy and coma [20-23]. Early and accurate measurement of blood concentrations of both D- and L- lactate in the blood is important for clinical diagnosis and to ensure the timely initiation of appropriate treatment.

Changes in blood constituent concentrations may occur after specimen collection. Serum or plasma samples that are

*Address correspondence to this author at the Department of Large Animal Clinical Sciences, Western College of Veterinary Medicine, University of Saskatchewan, 52 Campus Drive, Saskatoon, SK, S7N 5B4, Canada;

Tel: 306-966-7157; Fax: 306-966-7159; E-mail: k.lohmann@usask.ca not promptly separated from red blood cells following collection may contain artifactually high levels of lactate since red blood cells (RBC) can continue to metabolize glucose in vitro and produce both isomers of lactate. In general, it is recommended that serum and plasma for biochemical analysis be separated from cells as soon as possible and held no more than 4 hours at $4^{\circ} \mathrm{C}$ prior to processing to prevent ongoing cellular metabolism and transport of analytes between plasma or serum and cellular components [24]. However, outside the hospital and/or laboratory setting, this may not always be possible. For example, blood samples collected in the field may require storage for a period of time until their transport to a laboratory for analysis. Storage and processing delays may also occur within laboratories, especially when a large number of samples require analysis. Research has shown that even a fifteen minute delay in processing human whole blood samples at room temperature, or storage for 1 hour at $4^{\circ} \mathrm{C}$, can result in a significant overestimation of initial total lactate levels $[25,26]$, which may be due to an additional formation of L-lactate if plasma or serum is left in prolonged contact with cells [27]. However, to our knowledge, the effects of specimen collection and storage on the blood levels of D-lactate specifically are unknown. Since D-lactate can be produced by glucose metabolism via the glyoxylase system in RBC, there is a possibility of additional D-lactate production in plasma and/or serum samples stored in prolonged contact with blood cells. Therefore, we hypothesized that plasma or serum concentrations of both lactate isomers change over time if the samples are left in contact with blood cells. As D-lactic acidosis is a well known complication of neonatal calf diarrhea and biological samples from these animals are often collected in the field, calves were chosen for this study's objective to examine 
processing and storage-dependent changes of D- and Llactate concentrations in serum and plasma over time.

\section{MATERIALS AND METHODS}

\section{Subjects}

Blood samples were obtained from eleven healthy Holstein breed calves, seven to fifteen days of age, housed at the Dairy Barn of the Department of Animal and Poultry Sciences, College of Agriculture and Bioresources, University of Saskatchewan. From five of the eleven calves, both serum and plasma were prepared from the same blood collection. Six of the eleven calves were used for preparation of either serum ( 3 calves) or plasma samples ( 3 calves). All procedures were approved by the University of Saskatchewan's Animal Research Ethics Board, and adhered to the Canadian Council on Animal Care guidelines for humane animal use.

\section{Sample Collection and Analysis}

Blood (60-120 mL) was collected by jugular venipuncture in manually restrained calves. Samples were processed as shown in Fig. (1). Immediately following collection (time 0$)$, half of the blood $(30-60 \mathrm{~mL})$ was spiked with DL-lactic acid to add $3 \mathrm{mM}$ of each isomer $(3 \mathrm{mM} \mathrm{D}$ lactic and $3 \mathrm{mM}$ L-lactic acid; from now on referred to as "spiked" samples). The blood samples were spiked to mimic those levels seen in calves with acidosis. The remaining blood was left untreated (from now on referred to as "untreated" samples).

For each individual calf, half of the spiked and untreated blood samples, respectively, were distributed into tubes containing lithium heparin (Vacutainer@ ${ }^{\circledR}$ PST $^{\mathrm{TM}}$ Tubes; BD) for plasma preparation and the remaining blood was distributed into Vacutainer@ serum tubes with a proprietary thrombin-based medical clotting agent and a polymer gel (Vacutainer® Rapid Serum Tubes; BD or Micro Tube; SARSTEDT) for serum collection. Tubes were allowed to stand for 30 minutes at room temperature and were then centrifuged for separation of plasma or serum, respectively, or were stored in contact with blood cells at $4^{\circ} \mathrm{C}$.

For separation of plasma or serum prior to storage, tubes were centrifuged at 2,000 x $g$ for 15 minutes (Eppendorf 5804R Centrifuge; Eppendorf, Hamburg, Germany). Following centrifugation, $0.5 \mathrm{~mL}$ aliquots of plasma or serum (from now on referred to as "separated" samples), respectively, were placed into $1.5 \mathrm{~mL}$ microcentrifuge tubes (Eppendorf; Hamburg, Germany) and then stored at $4^{\circ} \mathrm{C}$ in a refrigerator alongside the uncentrifuged samples (from now on referred to as plasma or serum stored "in contact with cells"). One aliquot from each processing method was removed from the refrigerator and frozen at $-80^{\circ} \mathrm{C}$ at $1,2,4$, $8,12,24$ and 48 hours after collection. Prior to freezing, samples stored in contact with blood cells were centrifuged

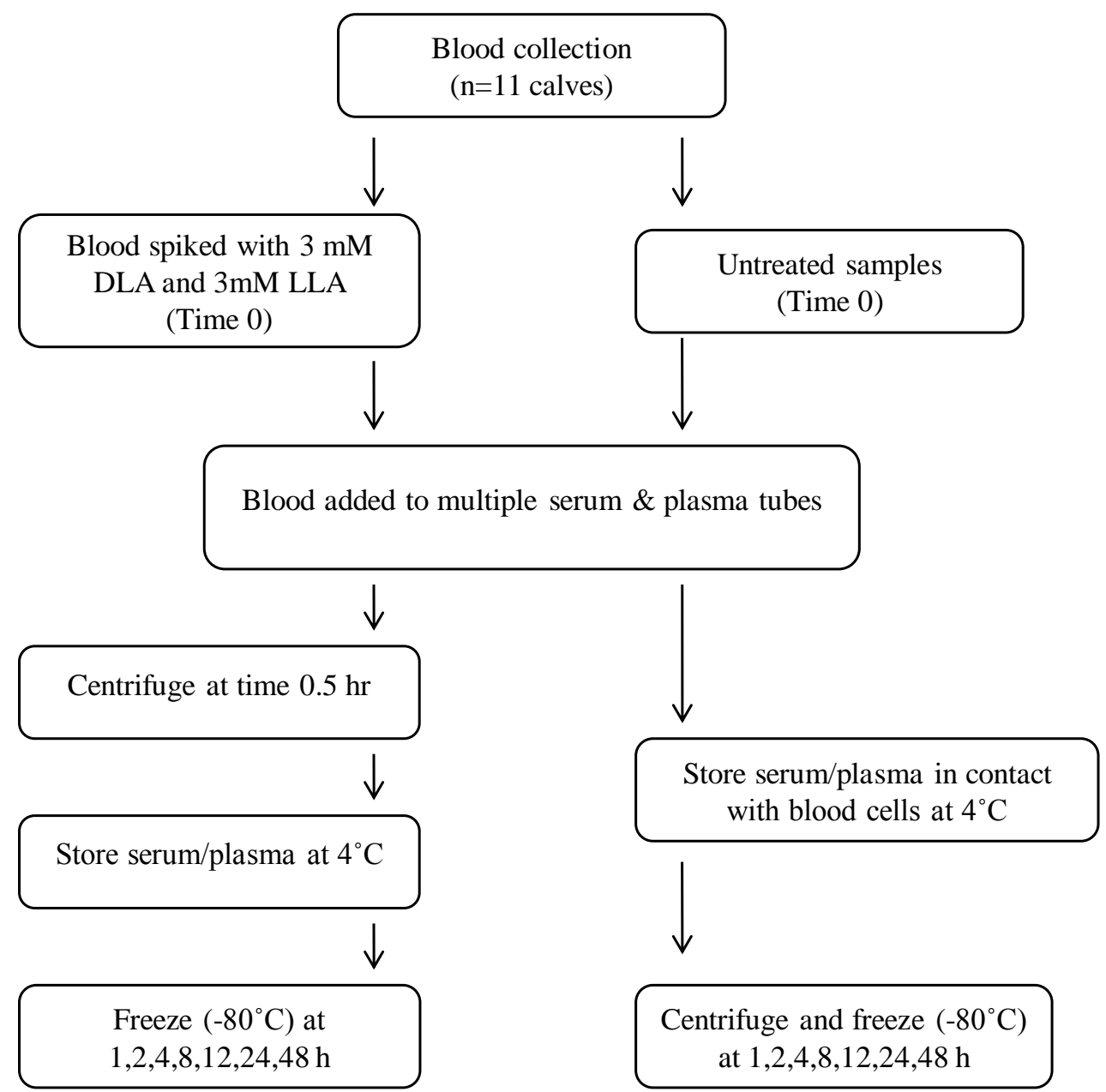

Fig. (1). Schematic flow chart of the study design and sampling handling processes. DLA, D-lactate, LLA, L-lactate. 
at 2,000 x $g$ for 15 minutes (AccuSpin Micro 17; Fishers Scientifica, Schwete, Germany) and plasma and serum harvested.

\section{D-Lactate and L-Lactate Measurement}

After thawing, D- and L-lactate concentration in serum and plasma samples were measured using enzymatic assay kits as per manufacturer's instructions (D-Lactate Colorimetric Assay Kit and Lactate Assay Kit, Biovision, Mountain View, CA, USA). Prior to their use, the kits were validated by two of the authors (B.B. Ling and J. Wright). Negative and positive controls, standards, blanks, samples and sample background were prepared as per manufacturer's instructions and analyzed in duplicate within each assay run. The positive control was prepared by diluting a known concentration of aqueous D-lactate solution $(10 \mathrm{mM})$ with calf plasma or serum. The negative control was prepared using only D- or L-lactate buffer. Standards were prepared by diluting an aqueous D-lactate solution $(10 \mathrm{mM})$ with assay buffer in concentrations of $500 \mu \mathrm{M}, 250 \mu \mathrm{M}, 100 \mu \mathrm{M}$, $50 \mu \mathrm{M}, \quad 25 \mu \mathrm{M}$ and $10 \mu \mathrm{M}$ as per manufacturer's recommendations. A calibration curve was made, in duplicate, in each assay run and D- and L-lactate concentrations were determined from the calibration curve. Within-run and between run precision was assayed in each batch by using positive controls in duplicate (CV was less than $15 \%$ for both D- and L-lactate respectively). The mean recovery of lactate isomers from plasma and serum samples was calculated from the positive control results. For the Dlactate assay, the mean recovery ranged from $96 \%-101 \%$ and for the L-lactate assay it ranged from $99 \%-105 \%$. The lower and upper detection limits of the assay kits are 0.01 and $10 \mathrm{mM}$, respectively, for D-lactate, and 0.02 and $10 \mathrm{mM}$, respectively, for L-lactate. In order to obtain accurate measurements within the assay kit detection limits, the spiked serum and plasma samples were diluted accordingly. The dilution factors in the spiked serum and plasma samples were taken into account in the final calculations. Total lactate concentrations were calculated by adding the D-lactate concentration and L-lactate concentration in each sample.

\section{Statistical Analysis}

Results are presented as mean \pm standard deviation (mean \pm SD) for all animals. The time-dependent changes of total, D- and L-lactate concentration in samples were analyzed using an Analysis of Variance (ANOVA) with Ryan-EinotGabriel-Welsch F-test as the post hoc test. As there was variability in blood processing time following initial collection, the 1 hour time point was chosen as the reference concentration value to which all subsequent concentrations were compared. The Ryan-Einot-Gabriel-Welsch multiple F test results were considered to be statistically significant if $\mathrm{P}$ $<0.05$. The changes in total lactate concentrations over time were further analyzed by linear regression. As both serum and plasma samples were obtained at the same time from a subset of calves $(n=5)$, the differences between serum and plasma D- and L-lactate concentration, respectively, were analyzed by a paired t-test. All statistics were calculated, and graphs created, using GraphPad Prism 5 for Windows (GraphPad Software, San Diego California, USA) and SPSS 13.0 (SPSS Inc., Chicago, IL, USA).

\section{RESULTS}

D- and L-Lactate concentrations in all separated serum and plasma samples were stable up to 48 hours (Figs. 2, 3). In untreated serum samples stored in contact with cells, Llactate concentration increased significantly by $48 \mathrm{~h}$ (increase of approximately $74 \% ; 3.75 \mathrm{mM}$ compared to 2.15 $\mathrm{mM}$; P<0.05; Fig. 2A). Similarly, D-lactate concentration in these untreated serum samples increased significantly by 48 h (increase of approximately $82 \% ; 0.708 \mathrm{mM}$ compared to $0.377 \mathrm{mM}$; P<0.05; Fig. 2C). In untreated plasma samples, a similar trend was apparent but the increase in L-lactate concentration (Fig. 2B) and D-lactate concentration (Fig. 2D) was not significant.

In spiked samples stored in contact with blood cells, a significant increase in L-lactate concentration at $48 \mathrm{~h}$ was evident in both serum (approximately 39\% increase; 7.26 $\mathrm{mM}$ compared to $5.21 \mathrm{mM}$; $\mathrm{P}<0.05$; Fig. 3A) and plasma (approximately $40 \%$ increase; $7.01 \mathrm{mM}$ compared to 5.00 $\mathrm{mM}$; $\mathrm{P}<0.05$; Fig. 3B) samples. D-Lactate concentration in these samples did not change significantly over time (Fig. 3C, D).

Total lactate concentration in untreated serum samples stored in contact with blood cells increased continuously over time and was significantly higher than the reference value at 48 hours (approximately $76 \%$ increase; $4.45 \mathrm{mM}$ compared to $2.52 \mathrm{mM}$; $\mathrm{P}<0.05$; Fig. 2E). No significant changes were observed in total lactate concentrations in separated serum samples (Fig. 2E) or in plasma samples regardless of storage conditions (Fig. 2F).

At baseline (1 hour) and at 48 hours, there was no significant difference between serum and plasma D- or Llactate concentrations $(\mathrm{P}>0.05)$.

\section{DISCUSSION}

In laboratory investigations, stability has been defined as "the capability of a sample for analysis to retain the initial property of a measured constituent for a period of time within specified limits when the sample is stored under defined conditions" (ISO Guide 30, 1992). Processing and storage of biological samples can have significant effects on stability and analytical reliability. Post-collection handling is known to change total lactate concentrations in human blood samples. Studies have shown that storage of whole blood, and serum or plasma with prolonged contact with blood cells, at both room temperature and $4^{\circ} \mathrm{C}$ can result in increasing total lactate concentrations over time [25-27, 30]. To preserve the initial concentration of blood lactate, it has therefore been recommended to separate serum or plasma from cells and keep samples cool or frozen during transport to the laboratory for analysis $[28,29]$. The use of specific antiglycolytic agents may stabilize blood lactate concentrations at room temperature for up to 24 hours prior to centrifugation [27]; however, these agents may not be feasible or available for use in remote areas in a clinical or diagnostic setting.

This study investigated the stability of both lactate isomers, D- and L-lactate, over time in bovine serum and plasma samples stored at $4^{\circ} \mathrm{C}$. Samples were stored after separation from blood cells by centrifugation or in contact 

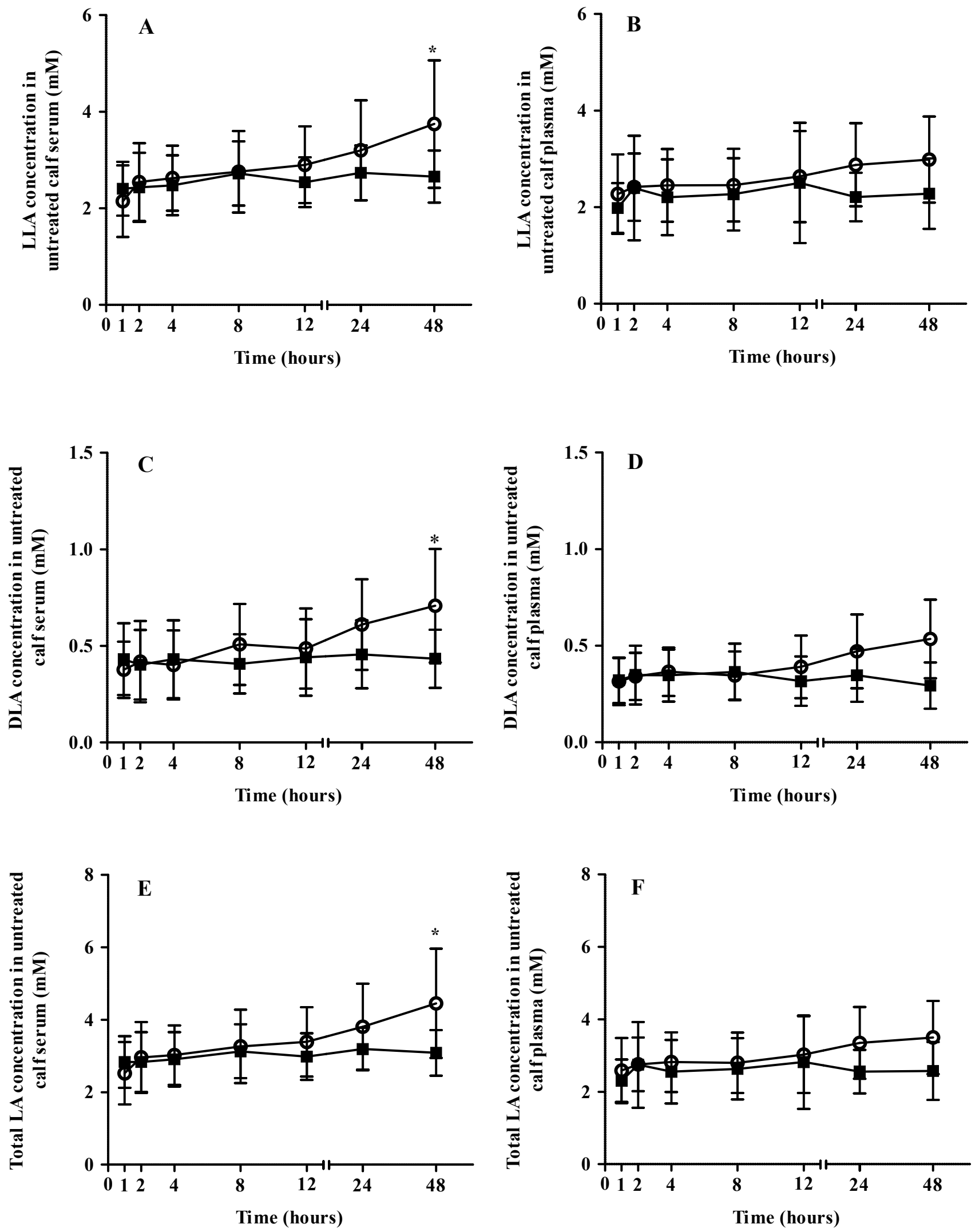

Fig. (2). Lactate concentrations (mean $\pm \mathrm{SD}, \mathrm{n}=8$ ) in untreated serum and plasma samples stored in contact with (contact, $\theta$, C) or separated from (separated, - $-\mathrm{S}$ ) blood cells. Samples were stored at $4{ }^{\circ} \mathrm{C}$ until the time point and transferred to $-80^{\circ} \mathrm{C}$ for long term storage. *Indicates that the Ryan-Einot Welsch multiple F test result was statistically significant $(\mathrm{P}<0.05)$. Serum $(\mathbf{A})$ and plasma $(\mathbf{B})$ L-lactate $($ LLA) concentrations were measured using using a Lactate Assay Kit. Serum (C) and plasma (D) D-lactate (DLA) concentrations were measured using a D-Lactate Colorimetric Assay Kit. Total lactate (LA) concentrations in serum (E) and plasma (F) were calculated by adding measured DLA and LLA concentrations. 

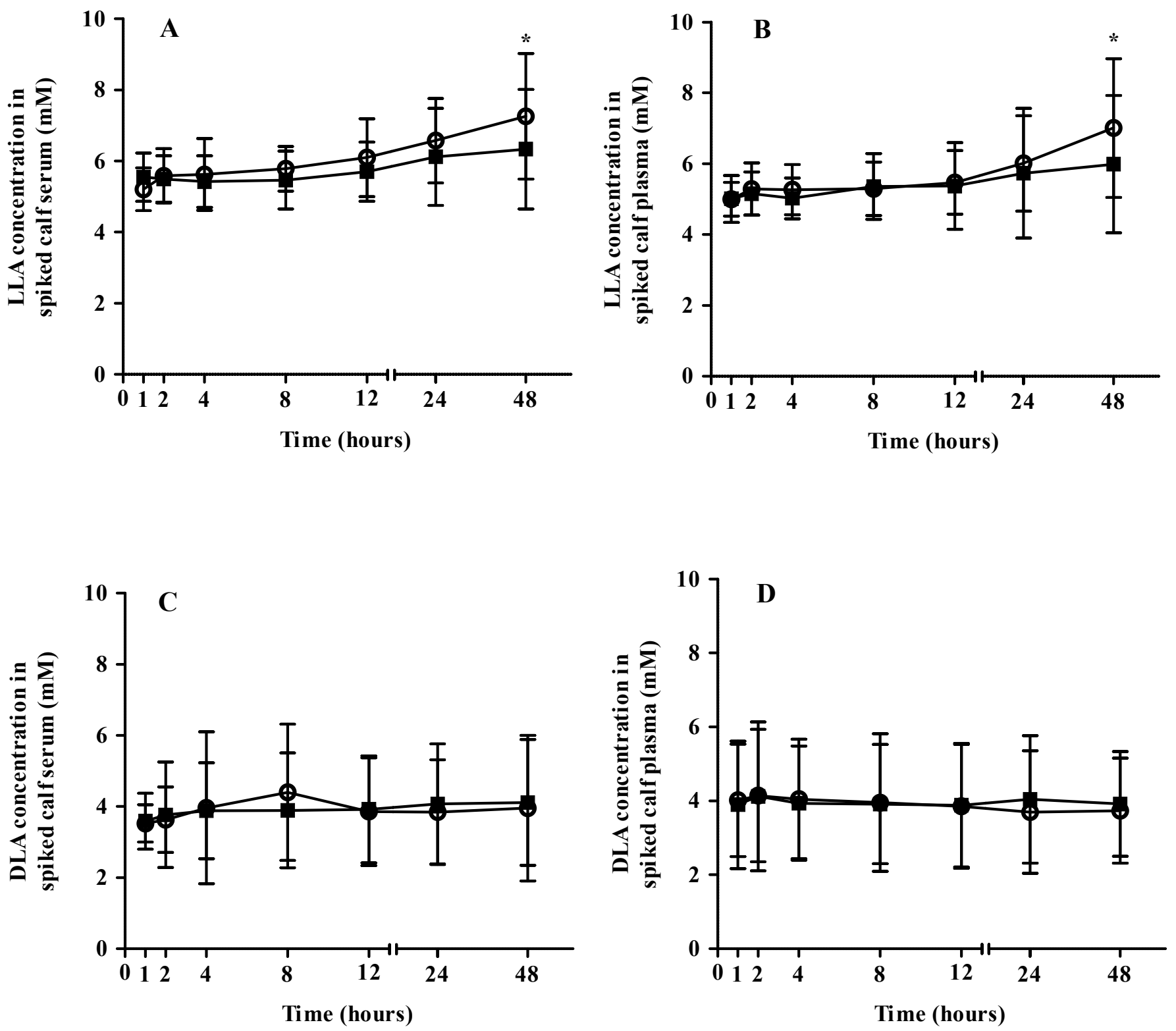

Fig. (3). Lactate concentrations (mean $\pm \mathrm{SD}, \mathrm{n}=8$ ) in spiked serum and plasma samples stored in contact with (contact, $\bullet$, C) or separated from (separated, - S) blood cells. Samples were spiked with DL-lactic acid to add $3 \mathrm{mM}$ of each isomer (3 mM D-lactic acid and $3 \mathrm{mM}$ Llactic acid) to the endogenous concentrations. Samples were stored at $4{ }^{\circ} \mathrm{C}$ until the time point and transferred to $-80^{\circ} \mathrm{C}$ for long term storage. *Indicates that the Ryan-Einot Welsch multiple F test result was statistically significant $(\mathrm{P}<0.05)$. Serum (A) and plasma (B) L-lactate (LLA) concentrations were measured using a Lactate Assay Kit. Serum (C) and plasma (D) D-lactate (DLA) concentrations were measured using a D-Lactate Colorimetric Assay Kit.

with blood cells. Though both lactate isomers can result in acidosis and lead to severe clinical symptoms at supraphysiological levels, the consequences of high D-lactate concentrations are different when compared to those of high L-lactate concentrations. Thus, it is important to be able to identify and quantify both isomers. Our study demonstrated that D-lactate concentrations in untreated serum samples stored in contact with blood cells increased over time and differed significantly from the 1 hour reference concentration at 48 hours $(\mathrm{P}<0.05)$. Though not statistically significant, a trend towards increased D-lactate concentration over time was also seen in the untreated plasma samples stored in contact with blood cells. D-Lactate production may continue after blood is collected as a result of the glyoxylase metabolic pathway. This pathway is present in the cytosol of all cells, including erythrocytes [31,32]. The glyoxylase system detoxifies and catalyses the conversion of methylglyoxal, a reactive glycating agent formed when carbohydrates, lipids, and amino acids are metabolized. In fact, methylglyoxal metabolism to D-lactate has been proposed as a detoxification pathway [31,33]. Increases in sample concentration of D-lactate due to this ongoing glyoxylase pathway in cells will likely be progressive over time since, once accumulated in vitro, D-lactate cannot undergo further metabolism [31,34]. We can only speculate that continued storage of plasma samples would eventually have resulted in a significant rise in D-lactate concentrations. 
We also found that L-lactate concentration increased over time in untreated and spiked serum samples, and in spiked plasma samples stored in contact with blood cells. This progressive increase in blood L-lactate concentration is likely due to ongoing glycolysis, in vitro, by all the cellular constituents, including platelets [27]. Glycolysis is the metabolic pathway by which glucose is converted to pyruvate and the enzymes required for this process are found in the cytoplasmic matrix of the cells. Pyruvate in blood samples will be reduced to lactate by the enzyme lactate dehydrogenase. In this process, NADH is oxidized to $\mathrm{NAD}^{+}$ and becomes available for the glyceraldehyde- 3-phosphate dehydrogenase reaction in the glycolysis pathway. As a result, blood glucose concentration will decrease and Llactate concentration will increase over time [27]. As this study did not measure glucose concentrations in samples, we could not confirm that this is the mechanism by which we observed, over time, increases in L-lactate concentration. In addition, as spiked blood samples rather than samples collected from clinically acidotic animals were examined in this study, care should be taken when extrapolating our results to clinical samples. Further studies should investigate the storage dependent changes in D- and L-lactate concentrations in serum and plasma, over time, in animals with clinical acidosis.

In our study, total lactate concentrations increased with time in serum samples stored in contact with blood cells, which is consistent with previous reports $[25,26]$. The differences reached statistical significance $(\mathrm{P}<0.05)$ at 48 hours when compared to the 1 hour reference samples. Other studies have demonstrated total lactate concentrations to be stable for up to 56 hours in human serum and plasma samples that were immediately separated from cells and stored at room temperature $\left(25^{\circ} \mathrm{C}\right)$ [26], and in rat plasma samples stored at $4^{\circ} \mathrm{C}$ [28]. The difference in stability of total lactate concentration observed in our study may therefore suggest a species or age effect.

For some assays, serum and plasma samples are considered to be equivalent while for others (i.e. bile acids, potassium, aldolase, lactate dehydrogenase) results obtained from serum and plasma samples can differ significantly to the point that clinical decisions are altered [35]. Several anticoagulants have been identified to retard blood cell glycolysis in vitro and thus affect the lactate production processes [27]. In our study, we used lithium-heparin which has limited effects on glycolysis in blood samples in vitro [36]. We found no significant difference between serum and plasma D- or L-lactate concentrations at 1 hour or at 48 hours.

In conclusion, our study was the first to investigate the stability of individual lactate isomers in bovine serum and plasma stored with or without contact with blood cells. Our results suggest that, to ensure a reliable measurement of Dand L- lactate concentrations, serum or plasma samples should be centrifuged and separated from cells as soon as possible following collection but can thereafter be stored at $4^{\circ} \mathrm{C}$ for up to 48 hours without noticeable changes in D- or L-lactate concentrations. Future research should aim to confirm our findings in samples from clinically acidotic animals and explore the effect of different anticoagulants or antiglycolytic agents in test tubes on D- and L-lactate concentrations.

\section{CONFLICT OF INTEREST}

The authors confirm that this article content has no conflict of interest.

\section{ACKNOWLEDGEMENT}

This work was funded by Natural Sciences and Engineering Research Council of Canada (NSERC) and Vitamin Settlement Grant Canada.

\section{REFERENCES}

[1] Kondoh Y, Kawase M, Ohmori S. D-lactate concentrations in blood, urine and sweat before and after exercise. Eur J Appl Physiol Occup Physiol 1992; 65: 88-93.

[2] Kondoh Y, Kawase M, Kawakami Y, et al. Concentrations of dlactate and its related metabolic intermediates in liver, blood, and muscle of diabetic and starved rats. Res Exp Med (Berl) 1992; 192: 407-14.

[3] Fitzgerald E, Mathieu S, Ball A. Metformin associated lactic acidosis. BMJ 2009; 339: b3660.

[4] Seidowsky A, Nseir S, Houdret N, et al. Metformin-associated lactic acidosis: A prognostic and therapeutic study. Crit Care Med 2009; 37: 2191-6.

[5] Lee YR, Powell N, Bonatti H, et al. Early development of lactic acidosis with short term linezolid treatment in a renal recipient. $\mathrm{J}$ Chemother 2008; 20: 766-7.

[6] Lewis LD, Phillips RW, Elliott CD. Changes in plasma glucose and lactate concentrations and enzyme activities in the neonatal calf with diarrhea. Am J Vet Res 1975; 36: 413-6.

[7] Weizman Z, Houri S, Ben-Ezer GD. Type of acidosis and clinical outcome in infantile gastroenteritis. J Pediatr Gastroenterol Nutr 1992; 14: 187-91.

[8] Lorenz I. D-lactic acidosis in calves. Vet J 2009; 179: 197-203.

[9] Soler PP, Garzon LP, Castilla FY, et al. D-lactic acidosis in an 11year-old patient with short bowel syndrome. An Pediatr (Barc) 2006; 64: 385-7.

[10] Ewaschuk JB, Naylor JM, Palmer R, et al. D-lactate production and excretion in diarrheic calves. J Vet Intern Med 2004; 18: 744-7.

[11] Di Grande A, Vancheri F, Giustolisi V, et al. Metformin-induced lactic acidosis in a type 2 diabetic patient with acute renal failure. Clin Ter 2008; 159: 87-9.

[12] Lalau JD, Race JM. Lactic acidosis in metformin therapy. Drugs 1999; 58 (Suppl 1): 55-60; discussion 75-82.

[13] Salpeter SR, Greyber E, Pasternak GA, et al. Risk of fatal and nonfatal lactic acidosis with metformin use in type 2 diabetes mellitus. Cochrane Database Syst Rev 2010; 4: CD002967.

[14] Omole OO, Nappert G, Naylor JM, et al. Both 1- and d-lactate contribute to metabolic acidosis in diarrheic calves. J Nutr 2001; 131: 2128-31.

[15] Ewaschuk JB, Naylor JM, Zello GA. Anion gap correlates with serum d- and dl-lactate concentration in diarrheic neonatal calves. $\mathrm{J}$ Vet Intern Med 2003; 17: 940-2.

[16] Petersen C. D-lactic acidosis. Nutr Clin Pract 2005; 20: 634-45.

[17] Lorenz I, Lorch A. D-lactic acidosis in lambs. Vet Rec 2009; 164 ; 174-5.

[18] Bleul U, Schwantag S, Stocker H, et al. Floppy kid syndrome caused by d-lactic acidosis in goat kids. J Vet Intern Med 2006; 20 : 1003-8.

[19] Uribarri J, Oh MS, Carroll HJ. D-lactic acidosis. A review of clinical presentation, biochemical features, and pathophysiologic mechanisms. Medicine (Baltimore) 1998; 77: 73-82.

[20] Kasari TR, Naylor JM. Clinical evaluation of sodium bicarbonate, sodium 1-lactate, and sodium acetate for the treatment of acidosis in diarrheic calves. J Am Vet Med Assoc 1985; 187: 392-7.

[21] Gentile A, Sconza S, Lorenz I, et al. D-lactic acidosis in calves as a consequence of experimentally induced ruminal acidosis. J Vet Med A Physiol Pathol Clin Med 2004; 51: 64-70.

[22] Forsyth RJ, Moulden A, Hull D. D-lactate associated encephalopathy in short bowel syndrome: Management with longterm non-absorbable oral antimicrobials. Clin Nutr 1991; 10: 3525. 
[23] Grunert S, Schmidts M, Kenzel S, et al. D-lactic acidosis: "Rightleft disorientation" In laboratory testing: Acute encephalopathy in a child with carbohydrate malabsorption syndrome. J Pediatr Gastroenterol Nutr 2010; 50: 106-7.

[24] Tuck MK, Chan DW, Chia D, et al. Standard operating procedures for serum and plasma collection: Early detection research network consensus statement standard operating procedure integration working group. J Proteome Res 2009; 8: 113-7.

[25] Calatayud O, Tenias JM. Effects of time, temperature and blood cell counts on levels of lactate in heparinized whole blood gas samples. Scand J Clin Lab Invest 2003; 63: 311-4.

[26] Boyanton BL Jr, Blick KE. Stability studies of twenty-four analytes in human plasma and serum. Clin Chem 2002; 48: 2242-7.

[27] Astles R, Williams CP, Sedor F. Stability of plasma lactate in vitro in the presence of antiglycolytic agents. Clin Chem 1994; 40: 132730.

[28] Peng TC, Hsu BG, Yang FL, et al. Stability of blood biochemistry levels in animal model research: effects of storage condition and time. Biol Res Nurs 2010; 11: 395-400.

[29] Stahl M, Brandslund I. Controlled storage conditions prolong stability of biochemical components in whole blood. Clin Chem Lab Med 2005; 43: 210-5.
[30] Toffaletti J, Hammes ME, Gray R, et al. Lactate measured in diluted and undiluted whole blood and plasma: comparison of methods and effect of hematocrit. Clin Chem 1992; 38: 2430-4.

[31] McLellan AC, Thornalley PJ. Glyoxalase activity in human red blood cells fractioned by age. Mech Ageing Dev 1989; 48: 63-71.

[32] Allen RE, Lo TW, Thornalley PJ. Purification and characterisation of glyoxalase II from human red blood cells. Eur J Biochem 1993; 213: 1261-7.

[33] Kalapos MP. Methylglyoxal and glucose metabolism: A historical perspective and future avenues for research. Drug Metabol Drug Interact 2008; 23: 69-91.

[34] Karg E, Papp F, Tassi N, et al. Enhanced methylglyoxal formation in the erythrocytes of hemodialyzed patients. Metabolism 2009; 58 976-82.

[35] Miles RR, Roberts RF, Putnam AR, et al. Comparison of serum and heparinized plasma samples for measurement of chemistry analytes. Clin Chem 2004; 50: 1704-6.

[36] Mikesh LM, Bruns, DE. Stabilization of glucose in blood specimens: Mechanism of delay in fluoride inhibition of glycolysis. Clin Chem 2008; 54: 930-2.

(C) Ling et al.; Licensee Bentham Open.

This is an open access article licensed under the terms of the Creative Commons Attribution Non-Commercial License (http: //creativecommons.org/licenses/bync/3.0/) which permits unrestricted, non-commercial use, distribution and reproduction in any medium, provided the work is properly cited. 